\title{
LA DETERMINACIÓN DE LA FILIACIÓN EN SITUACIONES TRANSNACIONALES: CUESTIONES PRÁCTICAS*
}

\section{THE ESTABLISHMENT OF FILIATION IN TRANSNATIONAL SITUATIONS: PRACTICAL ISSUES}

\author{
Ma Jesús SÁNChez CANO \\ Profesora Ayudante Doctora de Derecho Internacional Privado \\ Universidad San Jorge \\ Magistrado Suplente
}

Recibido: 04.05.2020 / Aceptado: 27.05.2020

DOI: https://doi.org/10.20318/cdt.2020.5666

\begin{abstract}
Resumen: Los problemas que suscita en la práctica el establecimiento de la filiación se acrecientan en supuestos transfronterizos, debido a los diferentes elementos internacionales que presentan este tipo de situaciones. La cuestión puede dar lugar a mayores dificultades cuando la filiación viene establecida por una autoridad extranjera y no ha accedido al Registro Civil español. Más aún, si existe contradicción entre la filiación establecida en virtud de inscripción registral extranjera y la que consta en el Registro Civil español. En estos casos cabe preguntarse cuál será la ley aplicable al establecimiento de la filiación y si es posible otorgar algún efecto a la documentación registral extranjera.
\end{abstract}

Palabras clave: filiación, Registro Civil, exequátur.

Abstract: The problems of establishing filiation in practice are increased in cross-border situations, due to the different international elements of such situations. The problem can be even more difficult when the filiation is established by a foreign authority and it has not been entered in the Spanish Civil Register. Furthermore, if there is a contradiction between the filiation established by foreign registration and that recorded in the Spanish Civil Register. In those cases, it is necessary to ask what law will be applicable to the establishment of the filiation and whether it is possible to give any effect to the foreign registration documentation.

Keywords: filiation, Civil Register, exequátur.

Sumario: I. Introducción. II. Análisis de la SAP León de 6 de Noviembre de 2019. 1.Breve descripción de los hechos y fundamentos jurídicos. 2. La determinación de la filiación como cuestión previa al litigio de carácter sucesorio. 3. Eficacia en España de la filiación determinada en el extranjero. 4. Examen del fallo de la SAP León 6 Noviembre 2019. III. Consideraciones finales.

\section{Introducción}

1. Los problemas que suscita en la práctica el establecimiento de la filiación se acrecientan en supuestos transfronterizos, debido a los diferentes elementos internacionales que presentan este tipo de situaciones, que requieren la intervención del Derecho Internacional privado. La cuestión puede dar lugar a mayores dificultades cuando la filiación viene establecida por una autoridad extranjera y más aún, cuando se presenta como cuestión previa a una cuestión principal, cuya solución depende del resultado de la primera. Respecto a la cuestión previa, hay que prestar atención a una serie de consideraciones: 
$1^{\text {a) }}$ Lo habitual en los supuestos en que se plantea una cuestión previa es llevar a cabo un reconocimiento incidental de la filiación, a fin de determinar si cumple los presupuestos que requiere la cuestión principal.

$2^{\mathrm{a})}$ En muchos casos la filiación determinada por las autoridades extranjeras no ha accedido al Registro Civil español.

$\left.3^{a}\right)$ Tampoco se ha instado el exequátur de la resolución extranjera en materia de filiación.

2. Estas tres circunstancias están presentes en el caso resuelto por la SAP León núm. 1347/2019, de 6 de Noviembre de 2019'. Se trata de un litigio en el cual el Tribunal examina si la recurrente ostenta la condición de heredera forzosa de la testadora, a los efectos de determinar si dispone de legitimación pasiva para instar la nulidad del testamento y, subsidiariamente, para solicitar la legítima. La controversia trae causa de la existencia de una contradicción entre la filiación establecida en virtud de inscripción registral mejicana, y la que consta en el Registro Civil español. Se plantean, por tanto, los siguientes interrogantes:

$\left.1^{\circ}\right)$ ¿Cuál es la ley aplicable al establecimiento de la filiación de la apelante?

$2^{\circ}$ ) ¿Cabe otorgar algún efecto a la documentación aportada por la demandante sobre registros y notarías del Estado de Méjico?

$3^{\circ}$ ) ¿Cuál es el procedimiento a seguir para solucionar la contradicción entre las inscripciones registrales española y mejicanas?

3. Teniendo en cuenta las preguntas formuladas, el presente trabajo abordará el estudio del régimen de la filiación en supuestros transfronterizos, partiendo de la SAP León de 6 de Noviembre de 2019, cuyos razonamientos jurídicos se analizarán.

\section{Análisis de la SAP León de 6 de Noviembre de 2019}

4. Como ya se ha avanzado, la SAP de León resuelve un recurso de apelación formulado por quien alega ser hija de la testadora y por tanto, heredera forzosa de la misma. La Sentencia de instancia dictaminó que la actora no reunía dicha condición, en tanto que, en realidad, era sobrina de la testadora, y en consecuencia, carecía de la legitimación activa para instar la nulidad del testamento, así como para la petición subsidiaria, en la que solicitaba la legítima. Por este motivo, la apelante impugna esta resolución con fundamento en una errónea valoración de la prueba, juntamente con la conclusión a la que se llega respecto a los hechos en que se asienta.

5. Por su parte, la Audiencia Provincial analiza la prueba documental aportada y deja bien sentado que:

$\left.1^{\circ}\right)$ La demandante aparece inscrita en el Registro Civil español como hija legítima del hermano de la testadora y de su esposa (filiación por naturaleza y matrimonial).

$2^{\circ}$ ) La demandante, con el fin de que tuviera una vida mejor, fue "dada" por sus padres biológicos a la testadora y su marido, quienes la tomaron a su cargo como si se tratase de una hija $\mathrm{y}$, además, la inscribieron en los registros mejicanos como hija legítima del matrimonio.

$\left.3^{\circ}\right)$ No consta en los autos la existencia de ningún procedimiento adoptivo.

$4^{\circ}$ ) Por la recurrente se presentó solicitud de reconocimiento de adopción promovida ante los tribunales mejicanos, en la cual se aportó la certificación de inscripción del Registro Civil español, que contradice abiertamente tanto la filiación como los datos de nacimiento que constan en la inscripción del registro mejicano. El tribunal mejicano rechazó el reconocimiento de la adopción- sin pronunciarse sobre la filiación- sobre la base de que en el registro mejicano consta inscrita una filiación biológica originaria.

${ }^{1}$ ECLI: ES:APLE:2019:1347. 
$5^{\circ}$ ) La demandante en el momento de su nacimiento residía en España y tenía nacionalidad española.

6. Con fundamento en lo que antecede, el Tribunal "ad quem" alcanza las siguientes conclusiones:

$1^{\circ}$ ) Dado que la recurrente residía en España y tenía nacionalidad española en el momento de su nacimiento, la filiación se rige por la ley española (art.9.4 Cc). La ley española establece que la filiación se determina en el momento del nacimiento (art.112 Cc.) y sólo puede tener lugar por naturaleza o por adopción (art.108 Cc.).

$2^{\circ}$ ) El cambio de filiación únicamente puede traer causa de una adopción, extremo éste que no ha sido acreditado por la actora.

$3^{\circ}$ ) La documentación sobre registros y notarías mejicana no produce efecto sobre la filiación determinada en el ámbito interno del Estado español y constituye una contradicción en la filiación, que únicamente puede solucionarse mediante la impugnación de la filiación en el RCE y el reconocimiento de la filiación no inscrita.

$4^{\circ}$ ) Salvo reconocimiento de la resolución extranjera, ni las resoluciones emitidas por los tribunales mejicanos vinculan a los tribunales españoles, ni las dictadas por éstos vinculan a aquellos.

$5^{\circ}$ ) La inscripción de nacimiento mejicana se basa en datos erróneos, facilitados por quienes la solicitaron, y ni la demandante los considera como ciertos, según se desprende de los datos que obran en las actuaciones.

7. Por todo lo que antecede, el Tribunal acuerda que no ha lugar al recurso y por ende, confirma la desestimación de la demanda.

8. Con carácter previo al estudio del fallo, parece oportuno explicar algunas particularidades sobre los puntos principales que conforman la decisión del Tribunal.

\section{La determinación de la filiación como cuestión previa al litigio de carácter sucesorio.}

9. El planteamiento de cuestiones previas de Derecho Internacional privado resulta habitual en los litigios en materia de sucesiones, debiendo resolverlas en primer lugar, en tanto que constituyen presupuestos de éstos. Destacan en este punto los problemas relacionados con la determinación de la filiación, de la cual depende la condición de heredero y por consiguiente, los derechos sucesorios ${ }^{2}$. En el caso analizado la cuestión principal era la sucesión mortis causa de la causante española, mientras que la cuestión previa consistía en determinar si la demandante era en verdad hija de la testadora y en consecuencia, tenía legitimación activa para impugnar el testamento, así como para solicitar la legítima.

10. Ni el Derecho Internacional Privado de la Unión Europea ni el Derecho Internacional Privado español proporcionan una respuesta a la denominada cuestión previa, aunque la doctrina se inclina por la tesis de la Lex Formalis Fori o "tesis de conexión independiente", para solucionar el problema. Esta teoría es la más solvente y supone la aplicación a la cuestión previa de la norma de conflicto prevista en el sistema de Derecho Internacional privado del foro, que será la que designe la ley reguladora de la misma. La respuesta de la cuestión principal, que se resolverá con posterioridad, dependerá igualmente de la ley designada por la norma de conflicto del foro aplicable a dicha cuestión ${ }^{3}$.

\footnotetext{
${ }^{2}$ Este asunto ha sido abordado por la Jurisprudencia española en diferentes resoluciones, sirvan de ejemplo la SAP Alicante (Sec. $9^{a}$ ) núm. 377/2016 de 30 septiembre (AC 2016\1963) y SAP Alicante (Sec.9 $9^{a}$ núm. 30/2009 de 26 enero (AC 2009\1116).

${ }^{3}$ Teniendo en cuenta la materia que ocupa el presente trabajo, cabe traer aquí a colación lo dicho por Carrascosa González, quien pone en este punto como ejemplo el Reglamento sucesorio europeo, "que acepta que todas estas cuestiones preliminares
} 
11. Dicho esto, resulta claro que, en el caso estudiado, no existiendo ningún instrumento internacional que regule la filiación en supuestos internacionales ${ }^{4}$, la norma de conflicto que corresponde aplicar a la cuestión previa es el art.9.4 $\mathrm{Cc}^{5}$. Más en concreto, desde la reforma efectuada por la Ley $26 / 2015$, de 28 de julio, el apartado $1^{\circ}$ del art.9.4 Cc es una norma de conflicto de orientación material, cuyo propósito es potenciar el establecimiento de la filiación por naturaleza. A tal fin, el art.9.4.1 ${ }^{\circ} \mathrm{Cc}$ dispone de puntos de conexión jerarquizados, que operan de manera subsidiaria y sucesiva para el caso de que no se pueda determinar la ley aplicable a la filiación con arreglo a lo dispuesto en el punto de conexión principal ${ }^{6}$. Así, en primer lugar, la determinación y el carácter de la filiación por naturaleza dependerán de lo dispuesto en la ley de la residencia habitual del hijo en el momento del establecimiento de la filiación. En su defecto o en el caso de no poder determinarse la filiación a través del primer punto de conexión, el art.9.4.1 ${ }^{\circ} \mathrm{Cc}$ remite al la ley nacional del hijo, fijando nuevamente el punto de conexión en el momento del establecimiento de la filiación. En último término, el citado precepto ordena aplicar la ley sustantiva española, cuando la ley nacional del hijo no permitiere el establecimiento de la filiación, y si el hijo careciere de residencia habitual y de nacionalidad ${ }^{7}$.

deben regirse por la Ley designada por la específica norma de conflicto, sea europea o sea nacional, correspondiente a dicha "cuestión preliminar" y que se halla en vigor en el Estado miembro cuyos tribunales conocen del asunto sucesorio". Deduce esta afirmación el citado autor del art. 67.1 RES en concordancia con el Cons. [12], de ahí que considere que ha de seguirse "tesis de la Lex Formalis Fori” o de la conexión independiente.". En consecuencia, cuando haya que dilucidar una cuestión sobre una concreta filiación natural antes de adjudicar el caudal de la herencia, dicho aspecto "debe regirse por la Ley designada por las normas de conflicto, europeas o nacionales, vigentes en el Estado miembro cuyas autoridades conozcan del asunto sucesorio, como apunta la doctrina más aquilatada." Puede ampliarse información consultando. Vid. A. L. CALVo CaraVACA Y J. Carrascosa GonzÁlez, Derecho Internacional privado, Vol.I, $18^{a}$ Edición, Comares, Granada, 2018, p.227.

${ }^{4}$ Se justifica la ausencia de normas de conflicto aplicable a la filiación en las normas consuetudinarias de Derecho internacional público, en cuya virtud corresponde a cada Estado la competencia exclusiva para decidir quienes son sus nacionales. Ello ha sido asumido por el TJUE en numerosas resoluciones, de entre las que destacan las SSTJUE 7 julio 1992, asunto C-369/90 (ECLI:EU:C:1992:295) y 2 marzo 2008, asunto C- 135/08, (ECLI:EU:C:2010:104). De igual modo, el TJUE ha tomado en consideración el "principio del mutuo reconocimiento", de tal manera que se deja al arbitrio de los Estados miembros la regulación de sus normas de conflicto con sus propios puntos de conexión para determinar materias relativas al estatuto personal, como la capacidad, el estado civil, el nombre y la filiación natural y adoptiva, resultando los demás Estados miembros obligados a dar efectos a las situaciones creadas válidamente al amparo de las normas de conflicto de otros Estados miembro, cualquiera que sea el punto de conexión que presenten. En este sentido, pueden citarse, entre otras muchas, las SSTJUE 14 octubre 2008, asunto C-353/2006 (ECLI:EU:C:2008:559), 22 diciembre 2010, asunto C-208/09, (ECLI:EU:C:2010:806) y 12 mayo 2011, asunto C-391/09 ( ECLI:EU:C:2011:291). Vid. también : J. CARrascosa GonZÁlez, "Ley aplicable a la filiación por naturaleza: de la ley nacional a la ley de la residencia habitual del hijo", Revista española de derecho internacional, Vol. $68, \mathrm{~N}^{\circ} 2,2016$, p. 161.

${ }^{5}$ Como ponen de relieve autores como Calvo Caravaca y Carrascosa González, no se han planteado soluciones generales ni respuestas específicas al problema de la cuestión previa, tampoco por parte de la jurisprudencia española. La teoría más aceptada es la conocida como "tesis de la Lex Formalis Fori", que ha sido acogida por las SSAP Alicante (Sec.9a) núm. 377/2016 de 30 septiembre (AC 2016\1963) y núm. 30/2009 de 26 enero (AC 2009\1116), ya mencionadas, así como el AAP Madrid (Secc.12a )núm. 25/2013 de 17 de enero de 2013 (ECLI:ES:APM:2013:841A). Vid. A.L. Calvo CaravacA y J. Carrascosa, Compendio de Derecho Internacional Privado, Rapid Centro Color S.L., Murcia, 2019, p.110.

${ }^{6}$ Para mayor información sobre el art.9.4 Cc en su redacción dada por la Ley 26/2015, pueden consultarse entre otras, las siguientes obras: J. CARRASCOSA GonzÁLEZ, "Ley aplicable a la filiación por naturaleza: de la ley nacional a la ley de la residencia habitual del hijo", Revista española de derecho internacional, Vol. 68, № 2, 2016, pp. 157-182, M.A. AdAm MuÑoz, "La nueva regulación de la filiación natural en el Derecho internacional privado español”, Cuadernos de Derecho Transnacional (Octubre 2016), Vol. 8, No 2, pp. 34-54, I. Lorente Martínez, "Filiación natural. el artículo 9.4 del Código Civil y el triunfo de la residencia habitual del hijo", Cuadernos de Derecho Transnacional ((Marzo 2018), Vol. 10, No 1, pp. 592-600). Por lo que respecta a la interpretación jurisprudencial de este precepto, Vid.: SSTS (Sala de lo Civil, Sección Pleno) núm 223/2018 y num. 224/2018, ambas de 17 abril (ECLI: ES: TS: 2018:1281 ECLI:ES:TS:2018:1282, respectivamente).

${ }^{7}$ Resulta muy intersante aquí la STS (Sala de lo Civil, Sección Pleno) núm 223/2018, antes referenciada, en la cual se deja sentado que el carácter de norma materialmente orientada del art.9.4.1 Cc supone que "además de la conexión con los criterios escogidos, también tiene en cuenta el contenido de las leyes en presencia y el resultado de su aplicación”. Esta resolución ha sido objeto de comentario por A.L. Calvo Caravaca y J. Carrascosa González, "Comentario de la Sentencia del Tribunal Supremo de 17 de abril de 2018 (1281/2017). La Ley aplicable a la filiación: la residencia habitual del hijo”, en M. YZQUIERDO Tolsada (Dir.), Comentarios a las Sentencias de Unificación de Doctrina (Civil y Mercantil), Año 2018 - Número 10, Dykinson, Madrid, 2019, pp. 237 a 247. Sobre esta sentencia, Vid. A. Durán AYAGO, "Sucesión temporal de normas de conflicto, art. 9.4 cc y regla ad hoc para resolver dos casos de filiación. a propósito de las sentencias del Tribunal Supremo, Sala de lo Civil, de 17 de abril de 2018", V.V.A.A., Crónica de Derecho internacional privado, REEI, pp.2-8. 
12. Sobre el mencionado artículo cabe precisar, en primer lugar, que se trata de una norma que, en tanto que persigue el favor filii, pone el acento en la persona del hijo y no en sus progenitores ${ }^{8}$. En segundo término, también, hay que resaltar que el art.9.4 Cc. solventa el problema del conflicto móvil, al fijar los puntos de conexión en el momento del establecimiento de la filiación. Sin embargo, algunos autores han observado que, aunque se trata de un planteamiento acertado, la redacción del precepto puede dar lugar a confusión, particularmente cuando se trata de interponer acciones judiciales para determinar la filiación, puesto que en el momento del establecimiento de la filiación por naturaleza, ésta no se encuentra determinada ${ }^{9}$. Por este motivo, se sostiene que, de llevarse a cabo una interpretación literal del art.9.4 Cc., en aquellos supuestos en que el hijo haya residido habitualmente en distintos Estados o haya detentado diferentes nacionalidades, no sería posible fijar el momento en que han de tomarse en consideración la residencia habitual o la nacionalidad del mismo y en consecuencia, tampoco determinar la concreta ley estatal aplicable a la filiación. Del mismo modo, como apunta algún sector doctrinal, la técnica de congelar los puntos de conexión en un momento determinado, favorece el fórum shopping $\mathrm{y}$ ocasiona inseguridad jurídica ${ }^{10}$.

13. De otro lado, por lo que respecta al punto de conexión principal del art.9.4 Cc., opina la doctrina que la aplicación de la ley de la residencia habitual es una opción realista y de todo punto acertada, dado que el punto de conexión nacionalidad, utilizado en el anterior art.9.4 Cc, podía conducir en mayor medida a la aplicación de una ley extranjera por los tribunales españoles. Asimismo, se ha puesto de manifiesto que el recurso a la residencia habitual es acorde con la actual situación de nuestro país como Estado de recepción de sujetos que poseen nacionalidad extranjera. Más aún, se dice que se trata de la solución más óptima, habida cuenta que representa una "conexión social" que contempla el vínculo entre el hijo y la sociedad en que se integra, frente a la nacionalidad, que bien pudiera representar un "vínculo meramente formal y aparente" conexión en materia de estado civil sigue siendo la nacionalidad, según se desprende del art.9.1 Cc, y por tal motivo la introducción de la residencia habitual como primer punto de conexión puede suscitar inconvenientes debido a la falta de armonía entre ambas normas ${ }^{12}$.

14. En lo referente al siguiente punto de conexión del art.9.4. $1^{\circ} \mathrm{Cc}$, se ha mantenido que la aplicación de la ley nacional del hijo, con carácter subsidiario a la ley de la residencia habitual, puede resultar previsible, dado que refleja una mayor proximidad con la identidad cultural de la persona, aunque se advierte que no en todo caso resulta ser la ley más vinculada a la situación y que en ocasiones, ni $\tan$ siquiera representa una vinculación suficiente ${ }^{13}$.

15. En relación a la conexión de cierre, que designa la ley sustantiva española como ley aplicable al establecimiento de la filiación por naturaleza, hay que indicar que contempla lo que se denomina "conexión judicial", toda vez que ordena la aplicación de la ley española en tanto que son los tribunales españoles los que entienden del litigio (Lex Materialis Fori, en este caso). Se trata de una "conexión materialmente orientada", cuya finaldad es garantizar en último término el establecimiento de la filiación cuando han fallado las conexiones anteriores y que, además, conduce a una ley previsible. En este punto, algún autor ha puesto de relieve que el recurso a la ley material española, previsto por el legislador español, propor-

\footnotetext{
${ }^{8}$ Así lo hace notar I. Lorente Martínez, "Filiación natural...cit”, p.594.

9 Sobre este particular, Adam Muñoz ha matizado que el art.9.4 Cc. en verdad alude al "presunto hijo", puesto que si la filiación no está establecida no puede haber un "verdadero hijo". Vid. M.D. AdAM MuÑOz, "La nueva regulación de la filiación natural...cit", p.38.

${ }^{10}$ Vid. A. L. Calvo Caravaca y J. Carrascosa González, Derecho Internacional privado, Vol.II, 17 a Edición, Comares, Granada, 2017, p.403, J. CARrascosa GonzÁlez, "Ley aplicable a la filiación...cit”, p.180, M. Guzmán Zapater, "La filiación internacional a examen por el Tribunal Supremo. A propósito de las sentencias TS 223 y 224 de 17 de abril de 2018", Cuadernos de Derecho Transnacional, 11, 2, Octubre 2019, pp. 624-635; y I. LORENTE MARTíNEz, "Filiación natural...cit”, pp.595 y 596.

11 Vid. J. CARrascosa GonzÁlez, "Ley aplicable a la filiación por naturaleza...cit”, pp.162 y 163.

12 P. De Miguel Asensio, "La Ley 26/2015 sobre protección a la infancia y a la adolescencia y la reforma del artículo 9 del Código Civil", recuperado en http://pedrodemiguelasensio.blogspot.com/2015/08/la-ley-262015-sobre-proteccion-la.html.

${ }^{13}$ Vid. J. Carrascosa GonzÁlez, "Ley aplicable a la filiación por naturaleza...cit”, pp.167-168.
} 
ciona una mayor seguridad jurídica en comparación con otras posibilidades, como la de aplicar la ley del país con la que el supuesto presente vínculos más estrechos. Ello, principalmente, porque evita a las partes el complejo proceso de probar cuál es el país con el que la filiación presenta una conexión más estrecha. Como nota negativa, se dice que la aplicación de la ley española, podría dar lugar a una resolución claudicante, que no desplegaría efectos en el Estado de la residencia habitual o de la nacionalidad del hijo ${ }^{14}$.

16. Por último, debe observarse que el legislador español no concreta los motivos por los cuales no es posible el establecimiento de la filiación en los ordenamientos jurídicos señalados por la ley de la residencia habitual o por la ley de la nacionalidad del hijo. Surge, por tanto, la duda de si el precepto ha de interpretarse de forma restrictiva o por el contrario, si debe recurrirse a una interpretación amplia del mismo, más acorde con la orientación material implícita en el art.9.4. ${ }^{\circ} \mathrm{Cc}$. Este último criterio parece ser el que más se ajusta a la voluntad del legislador y al espíritu de la norma, de tal manera que cabría admitir un amplio elenco de causas por las cuales no sería posible establecer la filiación, atendiendo a cada caso en particular. Aquí, siguiendo a Carrascosa González, cabe hacer varias consideraciones ${ }^{15}$ :

$1^{\mathrm{a})}$ No hay que desconocer que, en muchos casos, al aplicar el art.9.4.1 $1^{\mathrm{a}} \mathrm{Cc}$, se producirá una intervención anticipada del orden público internacional español. Ciertamente, el legislador español entiende que una ley que no permite el establecimiento de la filiación puede considerarse contraria a nuestro orden público internacional y en consecuencia, adelanta sus efectos, al mismo tiempo que evita el recurso a la excepción del art.12.3 $\mathrm{Cc}^{16}$.

$\left.2^{\circ}\right)$ El TS ha tenido ocasión de pronunciarse en su Sentencia 17 abril 2018, ya mencionada, y ha dejado sentado que únicamente cabe descartar la aplicación de la ley designada por el art.9.4. $1^{\circ} \mathrm{Cc}$ "cuando la ley aplicable excluya radicalmente la determinación de la filiación por razones incompatibles con los principios básicos de nuestro ordenamiento".

$3^{\circ}$ ) Consecuentemente con lo anterior, sería posible excluir la aplicación de la ley de la residencia habitual o en su caso, la de la nacionalidad del hijo y aplicar en su lugar, el Derecho español, en los siguientes supuestos:

a) Leyes extranjeras que no admiten o consideran ilegal la práctica de determinadas pruebas de filiación, como las biológicas.

b) Leyes extranjeras que no reconocen legitimación activa o pasiva para el ejercicio de acciones de filiación.

c) Leyes extranjeras que no permiten determinar la filiación por causas relativas al tipo de filiación, como, por ejemplo, la extramatrimonial, o por motivos de discriminación ${ }^{17}$.

\section{Eficacia en España de la filiación determinada en el extranjero.}

17. Dado que la Sentencia de la Audiencia Provincial de León plantea el problema que suscita la eficacia en España de la filiación determinada en el extranjero, parece oportuno examinar brevemente

${ }^{14}$ Vid. J. CArrascosa GonZÁlez, "Ley aplicable a la filiación por naturaleza...cit”, pp.169-171 y M.D. Adam MuÑOz, "La nueva regulación de la filiación natural...cit", pp.45 y 46.

${ }^{15}$ Para una completa información sobre esta cuestión, consúltese, J. CARRASCOSA GonzÁLEz, "Ley aplicable a la filiación por naturaleza...cit", p.173.

${ }^{16}$ Esta misma técnica se contempla igualmente en el art.10 RR-III respecto de las leyes extranjeras que no contemplan el divorcio o que impiden a una persona ejercitar acción de divorcio por causa de su sexo. Vid. J. CARrascosa GonzÁlez, "Ley aplicable a la filiación por naturaleza...cit", p.173.

${ }^{17}$ Por el contrario, no cabe descartar la ley de la residencia habitual y aplicar la ley nacional del hijo: (a) Cuando la determinación de la filiación perjudica al hijo (filiación llamada incestuosa); (b) Cuando concurren causas en relación con el transcurso del tiempo y/o prescripción de acciones de filiación; (c) Cuando los particulares no emplean los títulos legales para acreditar la filiación previstos en el Derecho extranjero. Ello, en tanto que los particulares no podrían alegar la aplicación de la ley nacional del hijo, puesto que pudieron determinar la filiación y no lo hicieron. Vid. J. CARrASCOSA GonZÁLez, "Ley aplicable a la filiación por naturaleza...cit", pp.174-175. 
la cuestión. Así, a este respecto, cabe distinguir entre los casos en que la filiación venga determinada por una sentencia extranjera y aquellos supuestos en que se pretenda el acceso al Registro Civil español de una filiación que conste en un Registro extranjero.

18. Comenzando por el reconocimiento de sentencias extranjeras, hay que señalar que la filiación así determinada podrá acceder al Registro Civil español previo reconocimiento por las autoridades españolas, según se deduce de los art.59 LCJIMC y 81-83 RRC. Ello significa que, en defecto de Convenio internacional aplicable en materia de filiación ${ }^{18}$, será necesario que la resolución extranjera obtenga el exequátur por la vía de los arts.41-61 LCJIMC. En este punto, hay que observar que el art.9.4 Cc. únicamente resulta aplicable cuando el establecimiento de la filiación se plantea ante las autoridades españolas, pero no lo es al reconocimiento de sentencias extranjeras sobre esta cuestión. De ahí que sea posible otorgar el exequátur en nuestro país a una resolución extranjera en materia de filiación que haya aplicado una ley distinta a la que conducirían las normas de conflicto española que hubiesen operado en el caso de que el asunto se hubiera formulado ante los tribunales españoles ${ }^{19}$.

19. Es necesario puntualizar también que el art. $82 \mathrm{RRC}$ prevé que si las sentencias y resoluciones firmes "contradicen hechos inscritos, deben ordenar para ser inscribibles, la rectificación correspondiente".

20. Por lo que se refiere al acceso al Registro Civil español de una filiación que figura en un Registro extranjero, operaría lo dispuesto en el Capítulo VI LCJIMC y en la D.A.Tercera de la LJV, junto con lo previsto en el art.81 RRC. En este sentido, es necesario que el documento extranjero en el que conste el establecimiento de la filiación tenga "fuerza en España con arreglo a las leyes o a los Tratados internacionales" (art.81 RRC). Aquí, debe tenerse en cuenta que, conforme al art.60 LCJIMC y el punto 1.c) de la D.A. Tercera de la LJV, la filiación contenida en el documento extranjero ha de ser válida de acuerdo con el ordenamiento designado por las normas españolas de Derecho internacional privado, en este caso, el art.9.4. $1^{\circ}$. $\mathrm{Cc}^{20}$. Se da la paradoja de que la ley exige el control de la ley aplicada por un Registro extranjero, pero no requiere dicho control si se trata de una sentencia judicial extranjera.

21. En este punto, hay que recordar que es posible impugnar ante los tribunales españoles la filiación legalmente determinada, en los casos previstos en la legislación civil (art.22. quáter d) LOPJ) y art.764 LEC). Del mismo modo, los tribunales españoles serían exclusivamente competentes para conocer de litigios sobre la validez o nulidad de las inscripciones practicadas en el RCE en materia de filiación (art.22. c) LOPJ).

\section{Examen del fallo de la SAP León 6 Noviembre 2019.}

22. A la vista de lo estudiado hasta el momento en los anteriores apartados del trabajo, resulta procedente examinar el fallo de la mencionada resolución, poniendo en relación los fundamentos jurídicos de la Sentencia, en particular, con las cuestiones analizadas en el epígrafe anterior.

23. Así, la Sala se pronuncia sobre cuál es la ley aplicable a la filiación, que opera como cuestión previa al litigio sucesorio. En este punto, el Tribunal acude a la norma de conflicto española, o lo que es lo mismo, al art.9.4 Cc, para concluir que la filiación en este caso se rige por la ley española, toda vez

\footnotetext{
${ }^{18}$ Como ejemplo de aplicación de Convenio internacional, cabe mencionar el AAP Madrid (Secc.14ª núm. 264/2008 de 21 octubre (AC 2009\40), que recurre al Convenio entre España y Alemania, sobre reconocimiento y ejecución de transacciones judiciales y documentos públicos con fuerza ejecutiva en materia civil y mercantil, de 14 de Noviembre de 1984, ratificado el 18 de Enero de 1988 y publicado en el B.O.E. de 16 de Febrero de 1988.

19 Vid. A.L. Calvo Caravaca y J. Carrascosa, Compendio de Derecho Internacional Privado, Rapid Centro Color S.L., Murcia, 2019, p.346.

20 A.L. Calvo Caravaca y J. Carrascosa, Compendio de Derecho Internacional Privado, Rapid Centro Color S.L., Murcia, 2019 , p.347.
} 
que la recurrente en el momento del nacimiento residía en España y tenía la nacionalidad española. Nada hay que objetar a este planteamiento, primeramente, puesto que, como se ha mencionado más arriba, la cuestión previa se rige por la norma de conflicto prevista en nuestro ordenamiento jurídico, habida cuenta que la cuestión se ha planteado ante los Tribunales españoles. En segundo lugar, se considera acertada la decisión de la Audiencia Provincial de León de aplicar la ley española designada por el art.9.4 Cc, puesto que el citado precepto fija los puntos de conexión en el momento del establecimiento de la filiación. Ciertamente, atendiendo a los antecedentes del caso y a las pruebas practicadas, ha quedado debidamente acreditado, en particular, a través de la inscripción en el RCE, que cuando se estableció la filiación, efectivamente, la actora residía en nuestro país y además, era española.

24. No obstante, hay que hacer notar que la Audiencia no concreta cuál es el punto de conexión aplicado para determinar que la ley española es la que rige la filiación en este supuesto. Evidentemente, dado que en el momento de interposición de la demanda estaba ya en vigor la versión del art.9.4.1 ${ }^{\circ} \mathrm{Cc}$ dada por la Ley $26 / 2015$, la Sala debió precisar que acudía, en primer lugar, al punto de conexión principal del citado precepto y que, en consecuencia, aplicaba la ley española porque la recurrente residía en España en el momento del establecimiento de la filiación.

25. En aplicación de la ley española, el Tribunal entiende que "los hijos no se "dan", puesto que la filiación en Derecho español sólo puede tener lugar por naturaleza y por adopción, conforme al art.108 Cc. Asimismo, la Sala recuerda que la filiación por naturaleza se produce desde el mismo momento del nacimiento (art. $112 \mathrm{Cc}$ ), y se acredita por la inscripción en el Registro Civil (art. $113 \mathrm{Cc}$ ). La respuesta dada por el Tribunal es correcta, puesto que no puede desconocerse que la ley designada por el art.9.4. ${ }^{\circ} \mathrm{Cc}$, en este caso la española, cubre extremos tales como los modos o títulos para acreditar la filiación, incluido el régimen jurídico de los medios de prueba de la generación ${ }^{21}$.

26. Teniendo en cuenta lo anterior, la Audiencia Provincial valora la prueba aportada por la actora, consistente en documentación mejicana sobre registros y notarías, y concluye que reflejan errores interesados por la demandante para alterar su verdadera filiación. Igualmente, la Sala observa que dicha documentación no puede producir efectos sobre la filiación determinada en el ámbito interno del Estado español y más aún, cuando comporta una contradicción en la filiación que únicamente es posible solventar impugnado previamente la filiación inscrita en el Registro Civil español y el reconocimiento de la que no aparece inscrita. Ante la solicitud de reconocimiento de adopción promovida ante los Tribunales mejicanos, insiste también el Tribunal en que "ni las resoluciones de los tribunales mejicanos vinculan a los tribunales españoles, ni las dictadas por estos vinculan a aquellos, salvo reconocimiento de la resolución judicial extranjera". En efecto, el razonamiento de la Audiencia concuerda con lo previsto para el acceso al RCE de la filiación establecida en el extranjero y en el art.59 LCJIMC, el punto 1.c) de la D.A. Tercera de la LJV y el art.81 RRC, así como con lo dispuesto en los art.59 LCJIMC y 81-83 RRC para el reconocimiento en España de sentencia extranjeras en materia de filiación ${ }^{22}$. Ello, sin olvidar que para la impugnación de la filiación legalmente determinada la LEC establece un procedimiento específico en los arts.764 y ss.

27. Por todo lo expuesto, la Sala atiende a la inscripción en el RCE de la filiación de la apelante, como hija del hermano de la testadora y de su esposa, para finalmente resolver que la demandante, en realidad, es sobrina de la testadora. En consecuencia, concluye la Audiencia que la recurrente carece de la condición de heredera forzosa que se atribuye. Por consiguiente, no cabe decidir sobre los derechos

${ }^{21}$ Ténganse en cuenta que el art.767.2 de la LEC contempla disposiciones sobre los medios de prueba aplicable a todos los litigios de los cuales conozcan los tribunales españoles, independientemente de la ley que gobierne la filiación en virtud del art.9.4 Cc. Vid. A.L. Calvo Caravaca y J. Carrascosa, Compendio de Derecho Internacional Privado, Rapid Centro Color S.L., Murcia, 2019, p.343.

${ }^{22}$ Recuérdese que el reconocimiento de las adopciones internacionales se regula en los art.25-30 LAI y opera salvo que la adopción se constituya al amparo del Convenio de La Haya de 1993 en materia de adopción internacional o de que exista Convenio bilateral sobe esta materia. 
sucesorios que le corresponderían, habida cuenta que carece de legitimación para solicitar la nulidad del testamento por preterición no intencional (art. 814, párrafo segundo y siguientes, del Código Civil) y para solicitar la reducción de la institución de heredero o los legados por preterición intencional."

\section{Conclusiones finales}

28. El presente trabajo ha puesto en evidencia algunos de los problemas prácticos que derivan de la filiación en supuestos internacionales, sobre todo, por lo que respecta a la aplicación de las normas de conflicto que designan la ley aplicable y de la eficacia de decisiones y documentos públicos extranjeros. De lo estudiado, cabe extraer las siguientes conclusiones:

29. Primera: Los tribunales españoles siguen encontrándose con problemas de aplicación de la norma de conflicto, como el denominado "cuestión previa", que, aún hoy en día, no encuentran con carácter general una solución legal ni en nuestras normas de producción interna ni en el Derecho de la Unión Europea, cuyas normas suelen simplemente remitirse al Derecho Internacional privado de los Estados miembros. Por este motivo, la mayor parte de nuestros órganos jurisdiccionales resuelven este tipo de cuestiones acogiendo la tesis de la Lex Formalis Fori, tradicionalmente admitida en el Derecho español. Esta solución resulta respetuosa con el art.12.6 Cc, que predica la imperatividad de la norma de conflicto y en consecuencia, obliga a Los Tribunales y autoridades a aplicar de oficio las normas de conflicto del Derecho español. Del mismo modo, siguiendo a Carrascosa González, esta teoría garantiza la exclusividad del Derecho Internacional privado español y proporciona seguridad jurídica. ${ }^{23}$

30. Segunda: Las soluciones que prevé el vigente art.9.4. $1^{\circ} \mathrm{Cc}$ resultan, en general, razonables con el principio de favor filii y dan respuesta a algunos de los problemas más comunes que derivan de la aplicación de las normas de conflicto, principalmente, por los siguientes motivos:

$\left.1^{\circ}\right)$ El art.9.4. $1^{\circ} \mathrm{Cc}$ contempla puntos de conexión de orientación material, dispuestos en cascada, que en último término, conducen a la aplicación de la ley sustantiva española, con el fin de facilitar la determinación de la filiación cuando no concurran las circunstancias de los anteriores puntos de conexión o no sea posible determinar la filiación a través de la ley designada por ellos.

$2^{\circ}$ ) El citado precepto fija en el tiempo los puntos de conexión mutables, como la residencia habitual y la nacionalidad, dando respuesta así a los inconvenientes que genera el conflicto móvil.

$3^{\circ}$ ) La incorporación de la residencia habitual como primer punto de conexión en el párrafo $1^{\circ}$ del art.9.4 Cc, relegando la nacionalidad a un segundo plano, se encuentra en sintonía con lo dispuesto en la actualidad en la normativa europea y convencional, y en particular, con el Convenio de La Haya de 1996, en materia de protección de menores, al que se remite el propio art.9.4 Cc. en su segundo párrafo para regular el contenido de la filiación y las relaciones paternofiliales. Ello, sin contar con que la conexión de la residencia habitual suele conducir a aplicar la ley del país donde el sujeto tenga su centro social de vida.

31. Tercera: De la ley designada por el art.9.4.1 $1^{\circ}$ Ce dependerá la determinación y carácter de la filiación natural y en consecuencia, el reconocimiento de la filiación, así como todo lo relativo al régimen de la prueba, sin perjuicio de las normas imperativas que resulten aplicables con arreglo a lo dispuesto en la ley del foro, cualquiera que sea la ley que rija la filiación. Esta misma ley también habrá de tomarse en consideración en el momento de llevar a cabo el control de la ley aplicada cuando la filiación acreditada por un documento extranjero pretenda acceder al RCE (art.60 LCJIMC y el punto 1.c) de la D.A. Tercera de la LJV).

23 Vid. A. L. Calvo Caravaca y J. Carrascosa González, Derecho Internacional privado, Vol.I, $18^{\text {a }}$ Edición, Comares, Granada, 2018, p.227. 
32. Cuarta. De la SAP de León de 6 de Noviembre de 2019 cabe especialmente destacar las consideraciones que se exponen a continuación:

$1^{\text {a) }} \mathrm{Al}$ aplicar la ley española a la cuestión de la determinación de la filiación de la demandante, conforme al art.9.4. $1^{\circ} \mathrm{Cc}$. el Tribunal hace una labor de concreción del momento del establecimiento de la filiación y en este sentido, concluye que la filiación se produce desde el nacimiento y queda legalmente determinada en el momento de la inscripción en el RCE, mediante la cual se acredita. Ello, lleva a la Sala a dejar sentado que la ley que rige en este caso la filiación es la española, pues en aquel tiempo la recurrente residía en España y además, tenía nacionalidad española.

$\left.2^{a}\right)$ El Tribunal, en aplicación de la ley española, razona que la filiación sólo puede tener lugar por naturaleza o por adopción (art.108 Cc), nunca por la simple atribución de la guarda de hecho a un familiar, como sucedió con la apelante, quien, en realidad, ha quedado probado por la inscripción del RCE que era sobrina de la causante.

$3^{\circ}$ ) La Audiencia aplica también la ley española designada por el art.9.4 Cc, para verificar la validez de la filiación que consta en los documentos registrales y notariales extranjeros y así, obtiene la conclusión de que son erróneos, habida cuenta que no se ha demostrado que la modificación de la filiación traiga causa de una adopción y en tanto en cuanto se ha puesto de manifiesto que existe una contradicción con la inscripción registral española. La decisión es razonable, ya que el orden público internacional español se opone a la inscripción en el RCE del acta registral mejicana.

$4^{a}$ ) Tiene razón el Tribunal cuando afirma que no puede dar efectos ni se encuentra vinculado por los a los documentos públicos y resoluciones extranjeros, puesto que, como se ha indicado, existen cauces establecidos legalmente a tal fin en la LCJIMC, la LJV y el RRC. Ello, sin perjuicio, del procedimiento específico previsto en la LEC para impugnar la filiación legalmente determinada. 